\title{
Ion Transition Height Distribution Obtained with the Satellite TAIYO
}

\author{
Shigeru MrYazAKI \\ Radio Research Laboratories, Tokyo, Japan
}

(Received September 5, 1978)

\begin{abstract}
Longitudinal and Latitudinal characteristics of the $\mathrm{O}^{+}-\mathrm{H}^{+}$ion transition height in the topside ionosphere at the low latitudes during the sunspot minimum period (1975-76) were observed by a retarding potential analyzer aboard TAIYO.

The results indicate that:

1) A semi-empirical formula of the ion transition height ( $H$ in $\mathrm{km})$ is expressed as a function of the solar zenith angle $(\chi$ in deg.) and the geomagnetic dip angle $(I$ in deg. $) ; H=591-87.1 \sin ^{2} I,\left(\chi \geqq 90^{\circ}\right)$, and $H=591-87.1$ $\sin ^{2} I+\left(217+473 \sin ^{2} I\right) \cos ^{0.331} \chi,\left(\chi \leqq 90^{\circ}\right)$.

2) The ion transition heights around the South Atlantic geomagnetic anomaly are rather variable than those at another region in the nighttime. The region with variable ion transition height roughly coincides with that of anomalous intense count observed with a high energy measuring instrument (SXR) aboard TAIYO in the ionosphere.

3) Discussions and comparisons with other experiments are given. The remarkable asymmetry of the ion transition heights between the southern and northern hemispheres is explained by the semi-empirical formula to some extent.
\end{abstract}

\section{Introduction}

The topside ionosphere consists of electrons and mainly $\mathrm{O}^{+}, \mathrm{He}^{+}, \mathrm{H}^{+}$ions. The distributions of these ion species are generally explained by the diffusive equilibrium along the magnetic field line, but there remain complex phenomena such as the equatorial anomaly at the low latitudes. Recently, Titheridge (1976) indicated that the diurnal variations of the ion transition heights in the northern and southern hemispheres were different from each other at longitudes around American zone, i.e., the ion transition heights in the southern hemisphere were lower than those in the northern hemisphere.

The observations of the ion concentration by the Explorer 32 indicated that the altitude of the $\mathrm{O}^{+}-\mathrm{H}^{+}$transition level depended strongly on longitude, that is, the ion transition heights at American longitudes $\left(330^{\circ} \mathrm{E}-20^{\circ} \mathrm{E}\right)$ were different 
from European and Pacific longitudes $\left(70^{\circ} \mathrm{E}-120^{\circ} \mathrm{E}\right.$ and $190^{\circ} \mathrm{E}-250^{\circ} \mathrm{E}$ respectively) (TAYLOR et al., 1965, 1968). BRINTON et al. (1970) explained this behavior as an effect caused by atmospheric winds. Recently, GledHILl (1976) mentioned various aeronomic effects caused by particle precipitation in the ionosphere at the South Atlantic geomagnetic anomaly.

This paper gives the observational results concerning the $\mathrm{O}_{-}^{+} \mathrm{H}^{+}$ion transition heights deduced from the retarding potential analyzer (RPA) aboard TAIYO.

\section{TAIYO-RPA Instrumentation}

The aeronomy satellite TAIYO was launched on February 1975, into an orbit with an inclination of $31^{\circ}$, perigee of $250 \mathrm{~km}$, apogee of $3,100 \mathrm{~km}$ and period of $120 \mathrm{~min}$.

One of the seven scientific instruments of TAIYO is an RPA. Normally an instrument of this category measures the total ion current as a function of a retarding potential. The total ion current flowing into a detector is the sum of each ionic component. When more than one kind of ions exist, it is rather difficult to determine the density and temperature from the DC current-voltage characteristic curve. Therefore the derivative of the ion current with respect to the retarding voltage is used. This method is a very effective one for the determination of the ion transition height, when there exist two ion species, $\mathrm{O}^{+}$and $\mathrm{H}^{+}$. That is, the $\mathrm{AC}$ current-voltage characteristic curve measured by this method shows that the peak value and its position change remarkably with ion mass for the measurement by a fast-moving vehicle. Accordingly, two ion species with sufficient different masses produce two maxima. The $\mathrm{O}^{+}-\mathrm{H}^{+}$ion transition height is given, when both maxima normalized by the factor of the value of the mass to the minus one-half power respectively are equal. The ion temperature must not be known, it is sufficient to assume a common temperature for both ion species.

The papers (Hirao, 1975; MiYazaki, 1975) include a more extensive description of the spacecraft TAIYO and the RPA.

\section{Longitudinal and Latitudinal Variations of the Ion Transition Heights}

The main ion species of the ionosphere in the region where TAIYO orbits are generally $\mathrm{O}^{+}, \mathrm{He}^{+}$and $\mathrm{H}^{+}$ions. Here, the two ion species, $\mathrm{O}^{+}$and $\mathrm{H}^{+}$are assumed to exist because the number of sunspots in 1975-76 is minimum. Since $\mathrm{He}^{+}$ions are minor constituent over the entire range during the period of low solar activity (TAYLOR et al., 1968), $\mathrm{He}^{+}$ions are not discussed here. 
Data stored by the tape recorder aboard TAIYO for a total of 117 paths of its revolution and some of the real time data during the period between March 1975 and October 1976, were used to investigate the longitudinal, latitudinal and diurnal variations of the $\mathrm{O}^{+}-\mathrm{H}^{+}$ion transition heights. The values of the planetary magnetic 3-hour-range indices $K_{\mathrm{p}}$ in 63 paths showed to be less than 2 , the $K_{\mathrm{p}}$ 's in 40 paths showed to be 3 or 4 , and the $K_{\mathrm{p}}$ 's in 14 paths showed to be larger than 5 . Thus, the most part of the observational period were under quiet condition.

Figure 1 indicates the observational results of $\mathrm{H}^{+}$ion density, $\mathrm{O}^{+}$ion density and the electron density distributions in arbitrary logarithmic scale. The innermost circle is the earth and the second circle is the satellite trajectory, therefore the distance between the two circles is proportional to satellite altitude. The second circle coincides with the base line for plasma density. The interval between two circles indicates the difference of one figure of the plasma density. The outer three circles show geomagnetic and geodetic latitude in deg., and local time in hour respectively.

Numbers on the second inner circle show the east longitude in deg. The solid circular arc just under local time circle indicates a region where $\mathrm{O}^{+}$ions

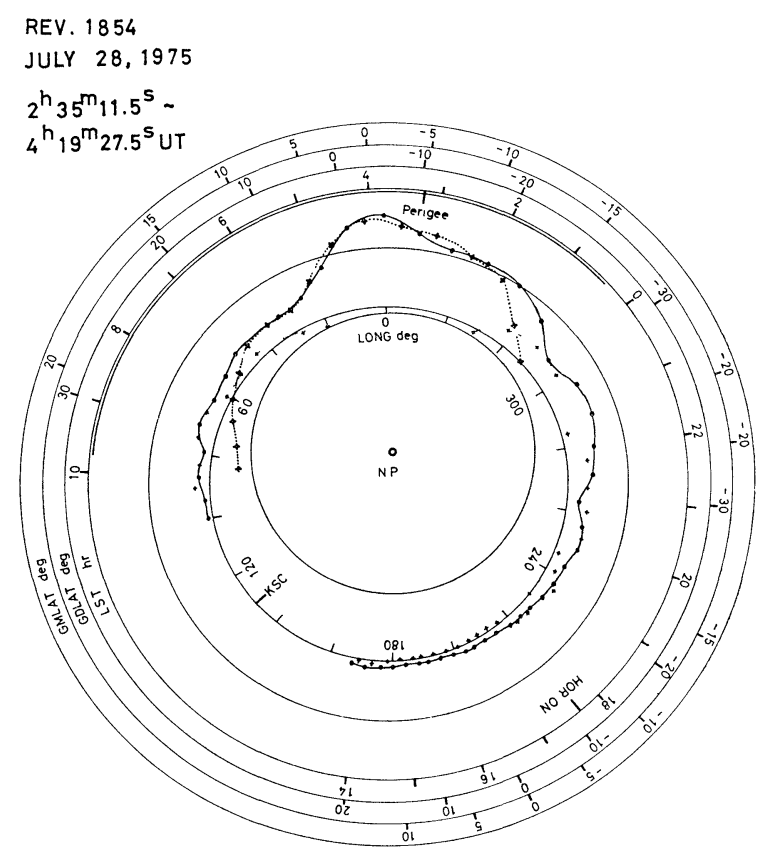

Fig. 1. $\mathrm{H}^{+}$ion density, $\mathrm{O}^{+}$ion density and electron density distributions observed by TAIYO-RPA. 
are observed. The line with the term "HOR. ON" means the time, when the RPA is operated by the horizon clock system aboard TAIYO.

A solid curve shows the electron density measured by the electron AC current of the first grid in the sensor of the RPA. The values of the electron density by the RPA are normalized with the impedance probe data. A dotted line shows the $\mathrm{O}^{+}$ion density and cross marks show the $\mathrm{H}^{+}$ion densities. The $\mathrm{O}^{+}$ and $\mathrm{H}^{+}$ion densities are calculated from the ion $\mathrm{AC}$ current of the collector in the sensor of the RPA, and the value of the sum of $\mathrm{O}^{+}$and $\mathrm{H}^{+}$ion densities is normalized with the electron density. As shown in Fig. 1, there are two points, where the $\mathrm{O}^{+}$ion density is equal to $\mathrm{H}^{+}$ion density at these heights, one ion transition height is in night side and another is in day side.

The circles in Fig. 2 indicate the longitudinal variation of the $\mathrm{O}^{+}-\mathrm{H}^{+}$ion transition heights for daytime between 06 and $18 \mathrm{hr}$ local time. The range of the geomagnetic latitudes of the data points lie within $\pm 40^{\circ}$ as the low inclination of the satellite trajectory. Although the data points are spread generally, the values between about $0^{\circ} \mathrm{E}-100^{\circ} \mathrm{E}$ are higher than those between about $200^{\circ} \mathrm{E}-300^{\circ} \mathrm{E}$. The cross marks in Fig. 2 show the nighttime ion transition height distributions. The range of the local time is between 18 and $06 \mathrm{hr}$. The ion transition heights are nearly constant over the whole longitudes, and spreading of the data points is smaller in contrast to the daytime condition.

Figure 3 shows the dip latitudinal variations of the $\mathrm{O}^{+}-\mathrm{H}^{+}$ion transition heights in the period of $06-18 \mathrm{hr}$ local time. Figure 4 shows the dip latitudinal variations of the ion densities in relative units at the ion transition heights. The values of the ion transition heights are minima at the dip equator and become larger towards high latitudes. The values of the ion densities at the ion transition heights show maxima at the dip equator and become smaller towards high



Fig. 2. Longitudinal $\mathrm{O}^{+-} \mathrm{H}^{+}$ion transition height characteristics in the daytime $(O)$ and nighttime $(+)$. 


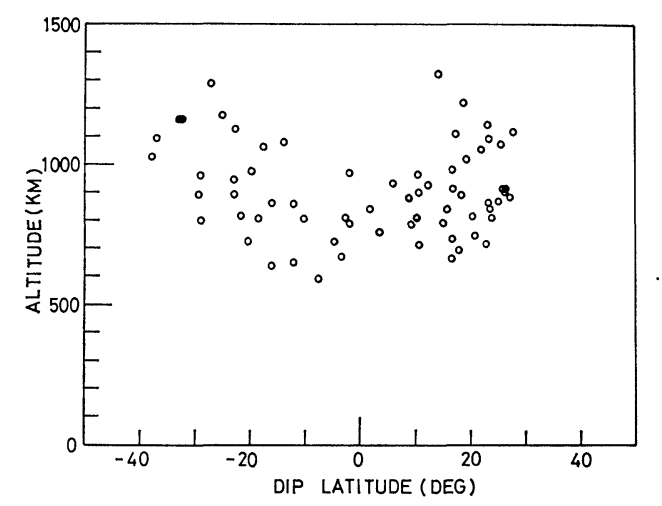

Fig. 3. Dip latitudinal $\mathrm{O}^{+}-\mathrm{H}^{+}$ion transition height characteristics in the daytime.

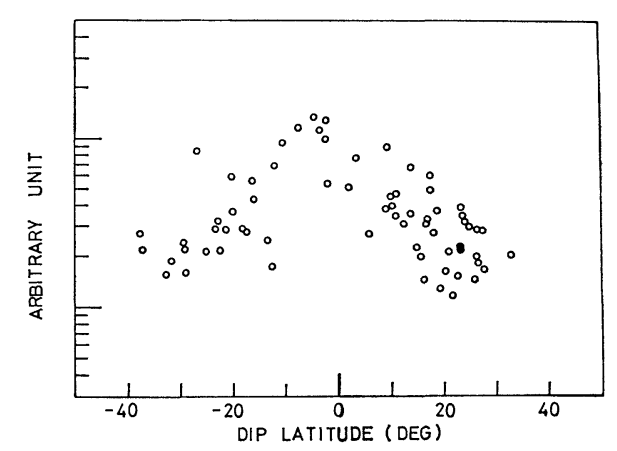

Fig. 4. The ion density variation characteristics at the ion transition heights against the dip latitudes in the daytime.

latitudes. In general, charged particle temperature increases from equator to high latitude (BRACE et al., 1967; Thomas et al., 1966), therefore $\mathrm{O}^{+}$and $\mathrm{H}^{+}$ ion density distributions shift to higher altitude, and the height of the maximum $\mathrm{O}^{+}$ion density moves in upward direction. Thus, the ion transition height changes with temperature and shifts to higher altitude from equator to high latitude (Angerami and Thomas, 1964). The ion density at the ion transition height is in inverse proportion to that height itself. This qualitative explanation agrees with the observational results as shown in Figs. 3 and 4 . On the other hand, the observational results in the nighttime indicate that the values of the ion transition heights are roughly constant over the dip latitudes between $-40^{\circ}$ and $+30^{\circ}$, and that the values of the ion densities around the dip equator exist in a wide range. 
4. Summary and Discussions

The main features of the present results are summarized below:

a) In the daytime, the ion transition heights exist in the altitude ranging $700-1,200 \mathrm{~km}$.

b) In the nighttime, the ion transition heights have nearly constant values of approximately $450-650 \mathrm{~km}$ in the whole longitudes.

c) The cases with rather low ion transition heights are located around the South Atlantic anomaly.

d) Concerning the dip latitudinal variations, the ion transition heights around the dip equator show a weak dependence on local time, on the contrary, the ion densities at the ion transition height are changing strongly. The daytime ion transition heights nearly coincide with the upper level of the equatorial anomaly about $700 \mathrm{~km}$ (KING et al., 1964).

e) From the items a) and b), and Figs. 3 and 4, it is shown that the ion transition heights are strongly changing with local time at higher dip latitudes. And the observational results indicate that the range of the ion density variation becomes small towards higher dip latitudes.

This type of problem has been considered by many investigators over the past years. Chandra et al. (1970) observed that $\mathrm{O}^{+}$ion density distribution shows the geomagnetic anomaly and DACHEV et al. (1976) also observed that $\mathrm{H}^{+}$ion density distribution shows the geomagnetic anomaly. These geomagnetic anomalies are caused by the $\boldsymbol{E} \times \boldsymbol{B}$ drift of charged particle across the magnetic field where $\boldsymbol{E}$ is the electric field by the dynamo effect and $\boldsymbol{B}$ is the earth's magnetic field. For the case of the geomagnetic anomaly in the electron density distribution, the analyses have been made by many investigators (BRAMLEY and Peart, 1964; Hanson and Moffett, 1966; Anderson, 1973a, b). As a qualitative interpretation of longitudinal and latitudinal variation of the ion transition height, the effect by the $\boldsymbol{E} \times \boldsymbol{B}$ drift is considered to be responsible. And also the neutral atmospheric wind in the $F$ region is responsible (Brinton et al., 1970). On the other hand, in the nighttime, it is considered that effects by the high energetic particles contribute in the South Atlantic anomaly region (HIRAO et al., 1975), therefore, those levels are rather variable than other regions.

One of the purposes of this section is to derive a semi-empirical formula for the ion transition heights in the observational results. The variations of the maximum electron density or plasma density and the height of the peak ion production rate are represented as a function of cosine of the solar zenith angle. Furthermore, the charged particle density is expected to be directly subject to geomagnetic control, as is actually the case. Physically, this is brought about the fact that diffusion of electrons and ions is influenced by the geomagnetic 
field (Yonezawa, 1966). There are two assumptions to be considered: (1) The formula for the ion transition height consists of two parts; one does not depend on the solar condition and another depends on the solar condition. (2) The formula is a function of $\sin I$ and $\cos \chi$ in the following.

$$
\begin{array}{ll}
H=H_{0}+a \sin ^{2} I, & \chi \geqq 90^{\circ}, \\
H=H_{0}+a \sin ^{2} I+\left(b+c \sin ^{2} I\right) \cos ^{d} \chi, & \chi \leqq 90^{\circ},
\end{array}
$$

where $\mathrm{H}$ is the $\mathrm{O}^{+}-\mathrm{H}^{+}$ion transition height in $\mathrm{km}, I$ is the magnetic dip angle in deg., and $\chi$ is the solar zenith angle in deg.

The five coefficients are determined from the observational data by a least squares method. These numerical figures are listed as follows.

$$
H_{0}=591, \quad a=-87.1, \quad b=217, \quad c=473, \text { and } d=0.331 .
$$

Figure 5 shows a graph of the formula of the ion transition height. Horizontal axis indicates the solar zenith angle, the left part from $180^{\circ}$ to $0^{\circ}$ shows the forenoon side and the right part from $0^{\circ}$ to $180^{\circ}$ shows the afternoon side. The value of the solar zenith angle depends on the geographic latitude, accordingly on the dip latitude. Therefore, there exist cases of absence of small solar zenith angle against to the value of the dip latitude.

Finally, comparing the observed results with other experiments are described in the following. The world wide changes in the ion transition height were deduced from Alouette I observations by Titheridge (1976). The mean diurnal variations in the ion transition heights both in the southern and northern hemispheres are generally similar to each other, but the amount of the ion transition heights in the southern hemisphere is lower than those in the northern



Fig. 5. A graph of the semi-empirical formula of the ion transition height deduced from the satellite TAIYO observations. 


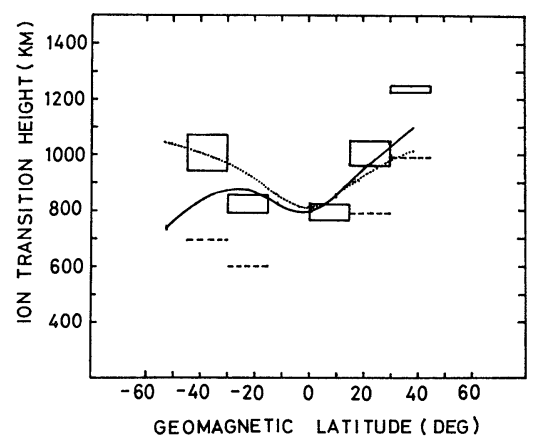

Fig. 6. The comparison between the results by TAIYO and Titheridge's results.

hemisphere. Especially, results in winter are $100-200 \mathrm{~km}$ lower in the southern hemisphere than in the northern hemisphere.

Figure 6 shows the comparison between the results by TAIYO and Titheridge's results. The geographic longitude is $285^{\circ} \mathrm{E}\left(75^{\circ} \mathrm{W}\right)$, that is, American longitude, and the local time is $12 \mathrm{hr}$. The solid line shows the case of the summer solstice in the northern hemisphere and the dotted line the winter solstice deduced from the semi-empirical formula. The rectangular shapes and the horizontal dashed lines indicate the ion transition heights at noon in summer and winter respectively, which are reproduced from Titheridge's Figs. 9 and 10. In summer case, there exists a local minimum around noon, and there exist local maxima before and after noon. Thus, the rectangular shape shows the range of the transition height in summer. The geomagnetic latitudinal variations in summer are generally similar to each other, this is also agrees qualitatively with the curves for summer daytime in Titheridge's Fig. 7, but there are some differences in magnitudes in winter case. However, the results by TAIYO also indicate the low ion transition height in the southern hemisphere. The remarkable asymmetry of the ion transition height between the northern and southern hemispheres is explained by the semi-empirical formula to some extent. Besides this, the extremely low ion transition height by Titheridge's results in winter may be concerned with the South Atlantic anomaly (GLEDHILL, 1976).

Concerning the longitudinal variation, characteristics of the ion transition heights for the longitudes of $135^{\circ} \mathrm{E}$ and $285^{\circ} \mathrm{E}$, are calculated applying the semiempirical formula. Figures $7 \mathrm{a}-\mathrm{f}$ indicate the calculated ion transition height distributions in longitude $135^{\circ} \mathrm{E}$ and $285^{\circ} \mathrm{E}$ at the equinox, summer and winter solstices in the northern hemisphere respectively. The horizontal axis shows the local time in hour, the vertical axis shows the altitude in $\mathrm{km}$ and the oblique axis shows the geodetic latitude from $-50^{\circ}$ to $+50^{\circ}$. The longitude of $285^{\circ} \mathrm{E}$ 

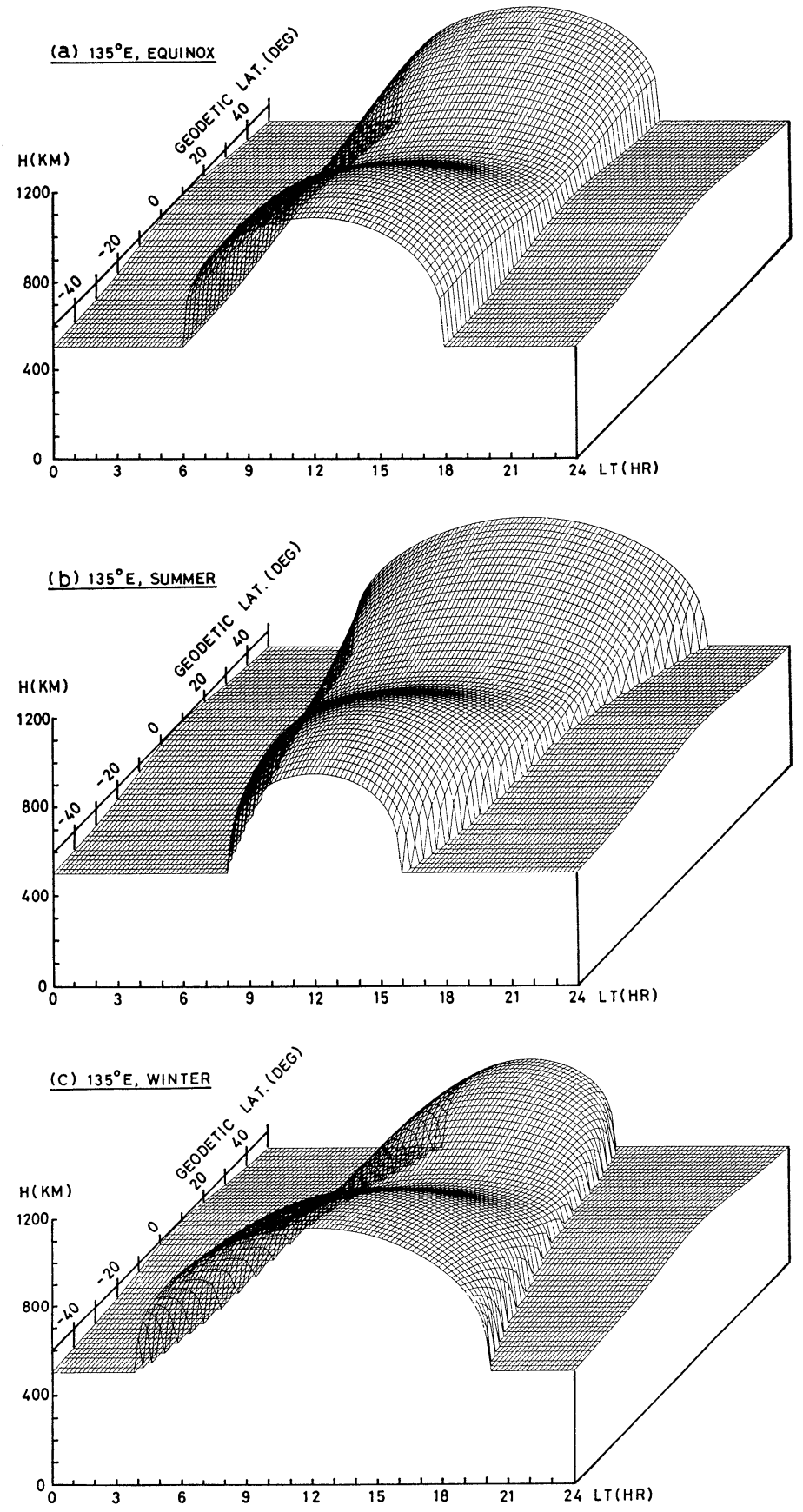

Fig. 7. The calculated ion transition height distributions versus the local time and the geodetic latitude in the cases of $135^{\circ} \mathrm{E}$ and $285^{\circ} \mathrm{E}$ longitudes. 
S. MIYAZAKI
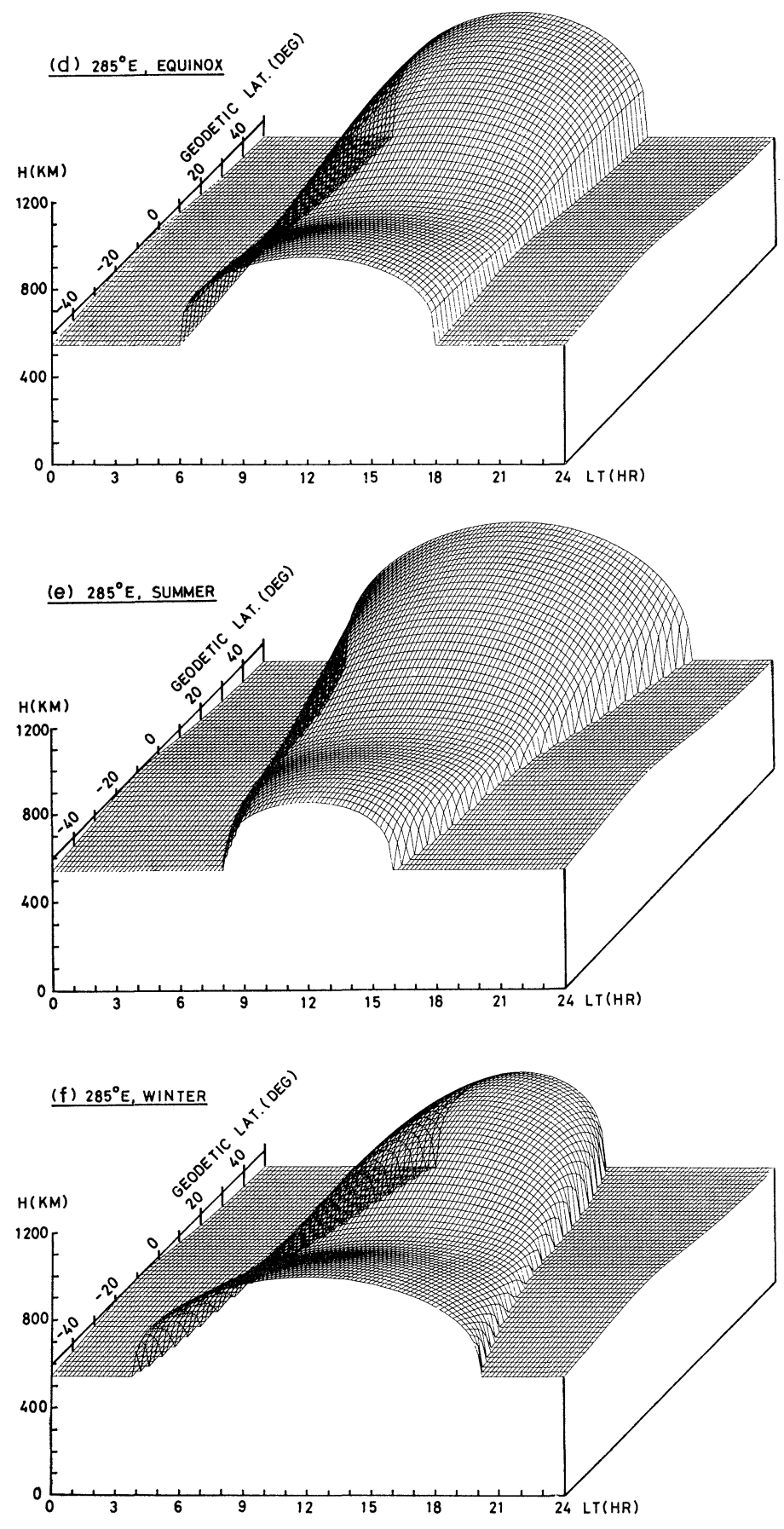

Fig. 7. (continued) 
is near the South Atlantic anomaly region and that of $135^{\circ} \mathrm{E}$ is in the Asian zone. For both longitudes, the values of the dip latitudes corresponding to the same geodetic latitude are rather different from each other, i.e., the dip equator at $135^{\circ} \mathrm{E}$ is in the northern hemisphere and that at $285^{\circ} \mathrm{E}$ is in the southern hemisphere. And also the effect by the change in the solar zenith angle is important. Although the ion transition height characteristics in both hemispheres are roughly symmetrical in $135^{\circ} \mathrm{E}$ longitude, those are remarkably asymmetrical in $285^{\circ} \mathrm{E}$ longitude. This fact shows that there exists longitudinal dependency in the ion transition heights, and this longitudinal dependency has been observed by TAYLOR et al. $(1965,1968)$ and BRINTON et al. (1970).

The author wishes to thank Prof. K. Hirao, the project manager of the third scientific satellite TAIYO and the late Prof. T. Tohmatsu, the chairman of the satellite TAIYO data management group, for their valuable discussions and continuous encouragement throughout the present work. Sincere thanks are due to Prof. H. Oya and his group for providing the impedance probe data and for their useful discussions. The author is also grateful to Dr. A. Dumbs for his critical reading of the manuscript. This research was supported by the Institute of Space and Aeronautical Science, University of Tokyo.

\section{REFERENCES}

Anderson, D.N., A theoretical study of the ionospheric $F$ region equatorial anomaly-I. Theory, Planet. Space Sci., 21, 409-419, 1973a.

ANDERson, D.N., A theoretical study of the ionospheric $F$ region equatorial anomaly-II. Results in the American and Asian sectors, Planet. Space Sci., 21, 421-442, $1973 \mathrm{~b}$.

ANGerami, J.J. and J.O. Thomas, Studies of planetary atmosphere. 1. The distribution of electrons and ions in the earth's exosphere, J. Geophys. Res., 69, 4537-4560, 1964.

Brace, L.H., B.M. Reddy, and H.G. MAYR, Global behavior of the ionosphere at $1,000 \mathrm{~km}$ altitudes, J. Geophys. Res., 72, 265-284, 1967.

Bramley, E.N. and M. Peart, Diffusion and electromagnetic drift in the equatorial $F_{2}$ region, J. Geophys. Res., 69, 4609-4616, 1964.

Brinton, H.C., H.G. MAYr, R.A. Picket, and H.A. TAylor, Jr., The effect of atmospheric winds on the $\mathrm{O}^{+-} \mathrm{H}^{+}$transition level, Space Res., 10, 652-662, 1970.

Chandra, S., B.E. Troy, Jr., J.L. Donley, and R.E. Bourdeau, OGO 4 observations of ion composition and temperatures in the topside ionosphere, J. Geophys. Res., 75, 3867-3878, 1970.

Dachev, Ts., D. Teodosiev, A. Bochev, and Yu. Matveichuk, Asymmetry in planetary distribution of ion density measured by Intercosmos-2 and 8 satellites, Paper presented to XIX COSPAR Plenary Meeting, Philadelphia, Pa., U.S.A., June 1976.

GledHill, J.A., Aeronomic effects of the South Atlantic anomaly, Rev. Geophys. Space Phys., 14, 173-187, 1976.

Hanson, W.B. and R.J. MofFetr, Ionization transport effects in the equatorial $F$ region, $J$. Geophys. Res., 71, 5559-5572, 1966.

HiraO, K., The TAIYO mission, J. Geomag. Geoelectr., 27, 265-270, 1975.

Hirao, K., M. MATSUOKA, and F. NAGAI, Anomalous intense count observed with SXR instrument aboard TAIYO in the ionosphere over South America, Abstract of the 58th Annual Meetings of Society of Terrestrial Magnetism and Electricity Japan, I-40, October 1975. 
King, J.W., P.A. Smith, D. Eccles, G.F. Fooks, and H. Helm, Preliminary investigation of the structure of the upper ionosphere as observed by the topside sounder satellite, Alouette, Proc. Roy. Soc., Ser. A, 281, No. 1381, 464-487, 1964.

MIYAZAKI, S., The retarding potential analyzer aboard the satellite TAIYO, J. Geomag. Geoelectr., 27, 311-320, 1975.

TAYlor, H.A., Jr., H.C. Brinton, and C.R. SMith, Positive ion composition in the magnetosphere obtained from the OGO-A satellite, J. Geophys. Res., 70, 5769-5781, 1965.

TAylor, H.A., Jr., H.C. Brinton, M.W. Pharo, III, and M.K. Rahman, Thermal ions in the exosphere; Evidence of solar and geomagnetic control, J. Geophys. Res., 73, 5521-5533, 1968.

Thomas, J.O., M.J. RyCroft, L. Colin, and K.L. Chan, The topside ionosphere. II. Experimental results from the Alouette I satellite, in Electron Density Profiles in Ionosphere and Exosphere, edited by J. Frihagen, pp. 322-357, North-Holland Publ. Co. Amsterdam, 1966.

Titheridge, J.E., Ion transition heights from topside electron density profiles, Planet. Space Sci., 24, 229-245, 1976.

Yonezawa, T., Theory of formation of the ionosphere, Space Sci. Rev., 5, 3-56, 1966. 